TRIBUTE

\section{Trace and tribute: Evan Weissman}

\author{
Matthew Potteiger* \\ College of Environmental Science and Forestry, \\ State University of New York
}

Special issue:

Food as a Tool for Social Change FALK $\mid \begin{aligned} & \text { Syracuse } \\ & \text { University }\end{aligned}$ loss continues to be felt on many levels throughout the local community, as well as in the Syracuse University Food Studies and Food Systems Planning communities. Evan and I were planning to meet to start working on the final edits of FoodPlanCNY, a comprehensive food system plan for Syracuse and Onondaga County, New York. We had worked closely on this project for over three years, ranging from brainstorming the initial aims and objectives to all the hours of team meetings, interviews with stakeholders, writing, revising, integrating the process into our teaching, deciding whether the page format should have two columns of text or three, and more revisions. Completed in his absence, the project is now a trace that evokes Evan's unique synthesis of deep ethics, rigorous scholarship, and community engagement.

This FoodPlanCNY project is dedicated to Evan and all that he was dedicated to. Evan's background and commitment to social justice and a collaborative, cross-disciplinary, and community-based approach to food system planning guided the core of the project. He made fundamental theoretical connections. I had served on his Ph.D. committee, so I was familiar with his grounding in political ecology and qualitative participatory methods. However, what I will always admire are certain moments, such as in an interview or during a stakeholder meeting, when Evan would identify a difficult issue and

* Matthew Potteiger, Professor, Department of Landscape Architecture, College of Environmental Science and Forestry, State University of New York, Syracuse; 1 Forestry Drive; Syracuse, NY 13210 USA; address for correspondence: 2696 Mill Street, Box 95; New Woodstock, NY 13122 USA; +1-315-427-9208; mpotteig@syr.edu 
initiate a dialogue that helped to reframe our understanding of it in a way that did not cast blame. His strong critiques of systemic inequalities reinforced his commitments to activism. He was also selfreflective and generous in his openness to different perspectives. We had many different ideas about the direction of the project, allocation of time and other resources, or how to conduct meetings, yet I could always trust his collaborative spirit.

Evan also brought people together. This is something integral to food and food systems work, and it suited him so well. His teaching style engaged students in various forms of community-based work that created new connections and networks. Students were involved in all stages and different levels of the FoodPlanCNY project, including translating the final recommendations into an action plan. Evan always had opportunities for students in mind and found several additional funding sources that helped to bring students into the process.

As the FoodPlanCNY project was wrapping up, he coordinated with public health professionals and other groups to strategize the next steps in the process beyond the final report. His effort was instrumental in helping to found and launch the Syracuse Onondaga Food System Alliance (SOFSA), a multisector food system organization with diverse community participation.

The work of SOFSA carries forward Evan's discussions with local organizations and government about how the whole process of food system coordination could be sustained and equitable. He felt it was important to engage some of the larger food producers in the region as well as those representing the interests of workers in those industries. Evan met these diverse, sometimes competing visions and dimensions of food system planning with fierce commitment and a big smile. 